\section{Pesquisa anatômica da glândula pineal em capivaras (Hydrochoerus hydrochoeris)}

\author{
Anatomical study of the pineal gland in capybara (Hydrochoerus \\ hrdrochoeris)
}

CORRESPONDENCE TO

Maria Angelica Miglino

Departamento de Cirurgia da

Faculdade de Medicina

Veterinária e Zootecnia da USP

Av. Prof. Dr. Orlando Marques

de Paiva, 87 - Cidade

Universitária Armando Salles de

Oliveira - 05508-900 - São Paulo

SP - Brasil

e-mail:miglino usp br

1. Conselho Nacional de Pesquisa e Desenvolvimento Processo 80.45.79/89.0

2. Departamento de Cirurgia

Faculdade de Medicina Veterinária e Zootecnia da USP - SP

3. Universidade Santo Amaro Santo

Amaro, Säo Paulo, SP e Escola

Paulista de Medicina, São Paulo, SP

4. Departamento de Patologia

Faculdade de Medicina Velerinária

e Zootecnia da USP.SP

5. Departamento de Apoio

Producão e Saúde Animai

Faculdade de Odontologia da

UNESP, Araçatuba, SP

\title{
RESUMO
}

A glàndula pineal foi estudada macro e microscopicamente em 19 capivaras (Hydrochoerus hydrochoeris) jovens e adultas, fêmeas e machos. A pineal, presente em todos os espécimes, estava localizada entre o cérebro e o cerebelo, e era formada por uma base com dois pedúnculos, uma haste e um ápice. A glândula localizava-se no teto do lll ventrículo, próximo ao colículo rostral. mostrando-se esbranquiçada ou acastanhada. O ápice continha uma cavidade. O comprimento médio da glândula na base foi de $1.3 \mathrm{~mm} ; 1,2 \mathrm{~mm} ; 2,0 \mathrm{~mm}$ na sua haste e ápice respectivamente. Revestida por uma cápsula de tecido conjuntivo contendo, pelo menos em parte do seu contorno, vasos sangüineos, o parênquima pineal mostrou pinealócitos com grânulos nucleares e células intersticiais.

\section{INTRODLÇ̃̃O}

$\mathrm{O}$ objetivo deste trabalho é pesquisar a morfologia da glindulal pincal da capivara (//ydrochoerus hrdeocheris). Nào encontramos na literatura consultada trabalho referente ato assinto, nesta especie.

De acordo com Schaffer ef al. ${ }^{1 \times}(1909)$, a glândula pineal esti presente em todos os vertebrados, exceto nos anfioxos. Entre os peixes clasmobrânquios è na maioria dos répteis. a pincal continua com o tereciro ventriculo, passando por uma abertura no crînio (forame parietal) e terminando sob a pele. numa pequena vesicula recoberta por epitélio ciliado. Em alguns répteis (por ex. Jatteria, cobra-cega. lagartos). estas vesículas tornam-se desenvolvidas numa estrutura que $\mathrm{ecm}$ aparência de um olho colho pincal). Sua parte superficial é mais espessa e forma um tipo de lente, enquianto que sua parte conectada com a haste é pigmentada c estratificada. semelhante a uma retina. notando-se, na haste sólida. fibras nervosas desenvolvidas.

l:m aves e mamileros o olho pineal não é desenvolvido e. segundo notas de Schaffer et al. ${ }^{18}(\mid 90)$ ). os ancestrais dos vertebrados devem ter tido umm par de olhos parietais, que podem ter sido periodicamente homologos aos olhos dos verlebrados (Ciross ${ }^{1}$. 1977).

Representando o olho pincal dos répteis, a epífise, segundo Kappers ${ }^{16}(1947)$, mostra grandes variações dentro das diversas ordens de mamiferos. Ela não está presente nos lidentata (creut/elds. 1912) e entre os Sirênios.

Pouco desenvolvida entre os cetáceos e os elefantes. ela é relativamente grande no equidna. nos marsupiais, nos roedores a nos ungulados.

Segundo Bailey el al.' (1973). todos os vertebrados cute possuem o sistema pineal apresentam, nos estagios embrionarios. um órgào saculilorme que mostra evaginaçoes secundárias e terciarias em algumas aves, onde se observam celulas pincais principais, entremeadas por células gliais. tecido conjuntivo o vasos.

Apesar da perda de funçào do olho, o órgào pineal persiste nos vertebrados superiores como uma estrutura glandular. () mesmo parece possuir função endócrina relacionada com sual capacidade original de perceber a luz.

Para Favilli" (1931) a pineal tem, como uma das suas mais distintas funções, a de regular. por secreça hormonal, o desenvolvimento dos órgàos genitais.

\section{MATERIAL E MÉTODOS}

Para realizar esta pesquisa utilizamos 19 capivaras

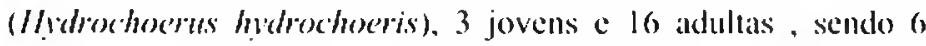
machos e 13 femeas, provenientes do Departamento de Zootecnia da Escola Superior de Agricultura Luiz de Queiro\% da Universidade de Sào Paulo. 
() animais foram sacrificados com injeção de anestésico, ou scja, uma associação de Ketalar ${ }^{\text {rk }}$ a $5 \%$ (Parke - Davis Laboratorio Aché Farmacêutico S.A.) e de Rompum ${ }^{\mathrm{k}}$ a $1 \%$ (Bayer do Brasil S.A.) na proporção de $0,5 \mathrm{mg}$ por quilo de peso.

No processamento do material os animais foram divididos em dois grupos: aqueles destinados ao estudo macroscópio tiveram suas cabeças injetadas com soluçào aquosa de formol a $20 \%$ seguida da remoçào das calotas cranianas e da imersão das peças em solução de formol a $10 \%$, com vistas à finalização do processo de fixação.

Este procedimento foi seguido pela dissecação e exposição da glândula, oportunidade $\mathrm{cm}$ que tomamos fotografias e as medidas correspondentes ao seu tamanho. As mensuraçôes foram realizadas com auxílio de um paquímetro.

Um outro grupo de animais (3) serviu para estudos microscópicos. Neste caso, os animais tiveram suas cabeças seccionadas para retirada das pineais. que foram fixadas isoladamente em solução de formol a $10 \%$ e submetidas a técnicas histológicas rotineiras, com o objetivo de obter cortes utilizados nos estudos estruturais da glândula.

Os cortes foram corados pela Hematoxilina-Fosina e as fotogralias das lâminas foram feitas com vários aumentos.

\section{RESULTADOS}

Os resultados desta investigaçào serão apresentados de acordo com os seguintes itens:

1. Anatomia macroscópica da glândula pineal

2. Anatomia microscópica da glândula pineal

\section{ANATOMIA MACROSCÓPICA DA GLÂNDULA PINEAL}

$\Lambda$ glândula pineal foi encontrada em todas as 19 capivaras (Hydrochoerus hidrochoeris) estudadas. Destes animais ( 13 fecmeas e 6 machos). 16 eram adultos (10 femeas e 6 machos) e 3 cram jovens (femeas).

De coloração branca perolada, às vezes ligeiramente acastanhada (Fig.l), a glândula pineal, bastante desenvolvida

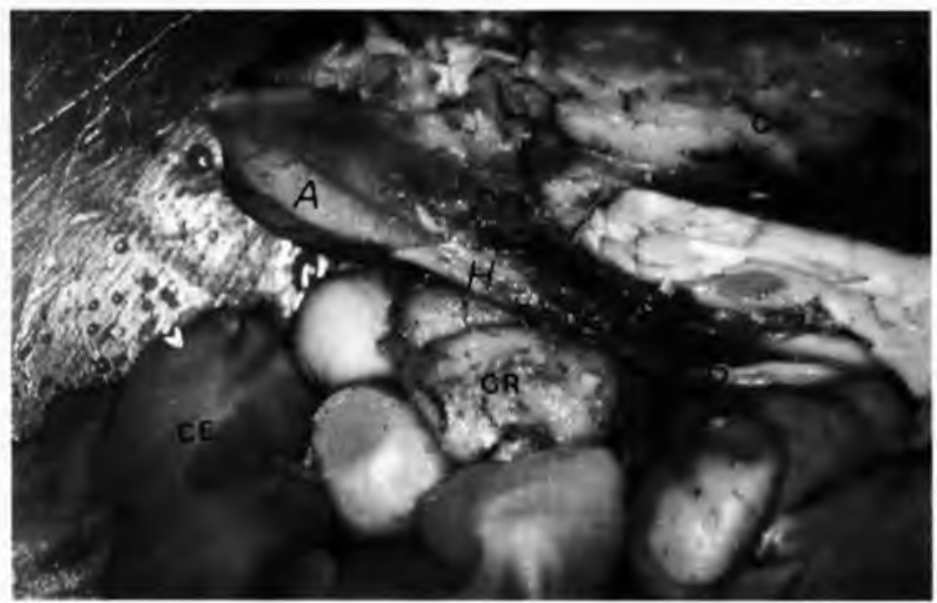

Figura 1

Fotografia do encéfalo (vista dorsal) da capivara (Hydrochoerus hydrochoeris) adulta onde se vê a glândula pineal, com suas três partes constituintes: ápice $(A)$, haste $(H)$ e base (B), esta última com seus dois pedúnculos (P) de inserção no Ill ventrículo. A glândula dispõe-se entre os coliculos rostrais (CR) insinuando-se entre o cérebro $(C)$ e o cerebelo (CE). Aumento: $2 x$ nestes animais, situava-se no teto do III ventrículo, assentando sobre os coliculos rostrais e insinuando-se entre o cérebro e o cerebelo, com seu maior cixo dirigido para a confluência dos scios durais, relacionando-se assim com o seio reto e a grande veia cerebral (Fig. 1). Em todos os casos, particularmente nos animais adultos. a glândula projetava-se além do contorno cerebral. sendo que nestes casos seu ápice achava-se envolto por uma tenda meningea especialmente formada pela dura-mater (Fig. 2). Fsta estrutura podia ser facilmente arrancada, se cuidados especiais nào fossem tomados durante o processo de remoçào das meninges e dissecação da glândula.

Posicionada então entre os lobos encefálicos occipitais e o verme do cerebelo, a glândula pineal possuía um formato alongado (Fig. 1), sendo classificada como de tipo $\alpha B C$.

A glândula presenta-se constituída por três partes distintas: un ápice mais dilatado, o qual insinua-se entre os henisférios cerebrais c o cerebelo ultrapassando os limites cerebrais; um corpo cilíndrico mais delgado que serve de conexão entre o ápice e a base do órgão (Fig. I). Esta, por sua ve\% pouco espessa, serve para inserir a glândula no teto do III ventrículo encefálico através de dois pedúnculos.

O ápice da glândula, de formato ovóide devido à sua dilataçào, mostrou macroscopicamente, quando seccionado, a presença de uma cavidade lembrando un lúmen relativamente grande.

Devido ao tamanho e ao formato da glândula, tomamos, de todos os órgãos, as medidas relativas ao comprimento e a largura, considerando neste último item, isoladamente, cada uma das suas partes.

Portanto, das 19 glândulas mensuradas verificamos que o comprimento da glândula pincal dos animais adultos variou de 0,5 $\mathrm{cm}$ a $3,0 \mathrm{~cm}$, sendo que 3 preparaçòes apresentaram comprimento igual a $2,0 \mathrm{~cm}$ c o comprimento médio para adultos foi igual a 2,2 $\mathrm{cm}$.

Quanto a largura da pineal, verificamos que sua base mediu $\mathrm{cm}$ média de $1,0 \mathrm{~mm}$ a $2,0 \mathrm{~mm}$ nos adultos e de $0,5 \mathrm{~mm}$ a $1,0 \mathrm{~mm}$ nos jovens. $\Lambda$ medida da sua haste variou de $1,0 \mathrm{~mm}$ a $2.0 \mathrm{~mm}$ nos adultos e de $0,5 \mathrm{~mm}$ a $1,0 \mathrm{~mm}$ nos jovens. Seu ápice mediu de 1,0 $\mathrm{mm}$ a $3.0 \mathrm{~mm}$ nos adultos e de $1,0 \mathrm{~mm}$ a $1.5 \mathrm{~mm}$ nos jovens.

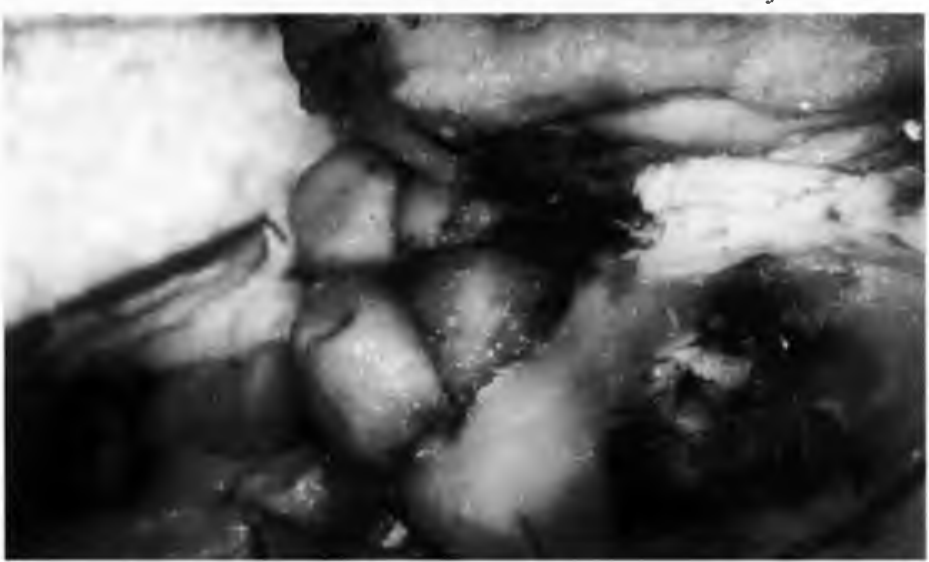

Figura 2

Folografia doápice (A) da glândula pineal (P) da capivara (Hydrochoerus hydrochoeris), mostrando a cápsula meníngea (M) que envolve $o$ ápice da glândula, quando ela ultrapassa o limite encefálico dorsal. Aumento: $2 x$. 


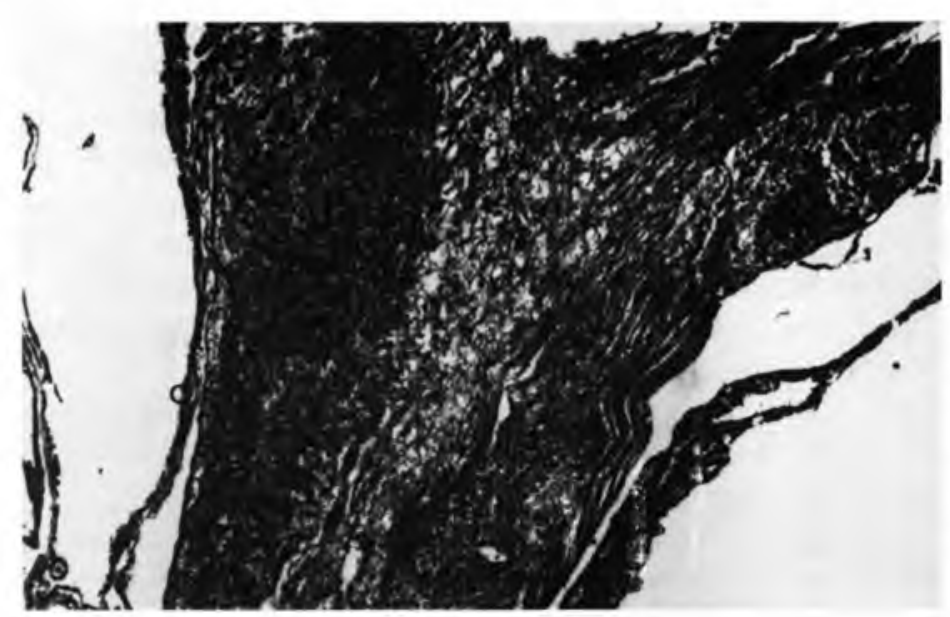

Figura 3

Fotomicrografia de corte longifudinal da base da glândula pineal da capivara (Hydrochoerus hydrochoeris) adulta, mostrando os seus pedúnculos de inserção no III ventrículo enecefálico (PE), e o arranjo do tecido pineal (P) e de tecido conjuntivo (C) (cápsula glândula). Coloração: H.E. Aumento: $66 x$.

Portanto. a largura média da base. da haste e do ápice loi igual a $1.3 \mathrm{~mm}$; $1.2 \mathrm{~mm} ; 2.0 \mathrm{~mm}$ para adultos $\mathrm{c} 0.8 \mathrm{~mm}: 0.0 \mathrm{~mm}$ e $1.3 \mathrm{~mm}$ para jovens, respectivamente.

\section{ANATOMIA NICROSCÓPICA DA GIÂNDULA PINEAL.}

$A$ análise dos cortes histológicos das diversas partes (base. hasitc c ápice) da glândula pincal de 2 capivaras (/lideochoerus hadrochoeris) adultas mostrou que o orgão esta principalmente constituido por pincalócitos, ou scja, células poliedricas possuidoras de ciloplasma abundante e núcleos arrendondados, os quais em menor aumento conferem à glândula um aspecto homogêneo e uniforme (lig. 3).

A basce da glândula, inserida alravés dos seus pedinculos no tecido nervoso do III ventriculo encefálico. mostra em menor aumento a disposiçaio de tecidos glandular. conjuntivo e nervoso (fig. 3). A haste da pincal, porção intermediária entre a base co apice, mostra em corte o arranjo do tecido glandular, entremcado

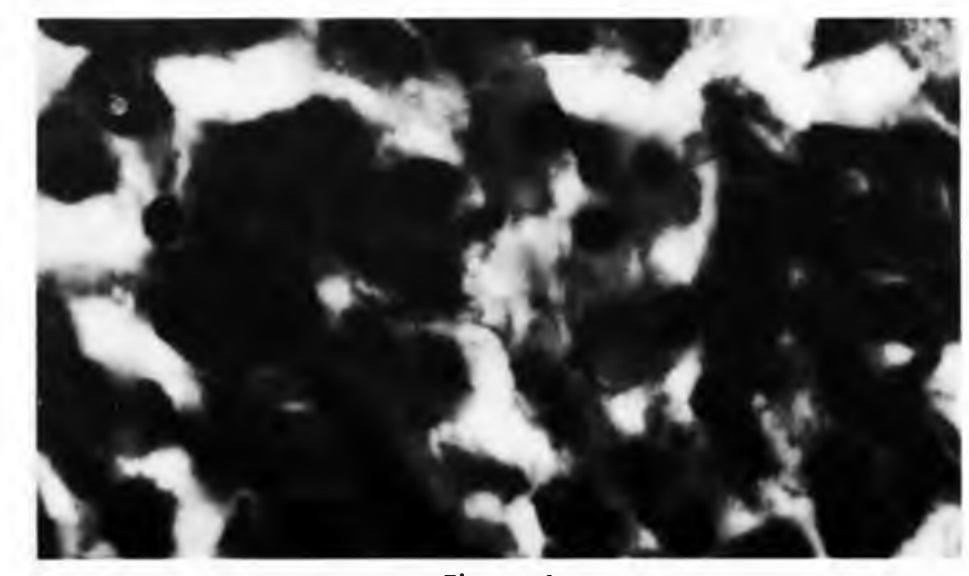

Figura 4

Fotomicrografia de um corte transversal do ápice da glândula pineal de capivara (Hydrochoerus hydrochoeris) adulta, mostrando as células pineais (pinealóciłos) (P), seus citoplasmas e seus núcleos arredondados, com condensaçōes granulares. Coloração H.E. Aumento: 1650x.

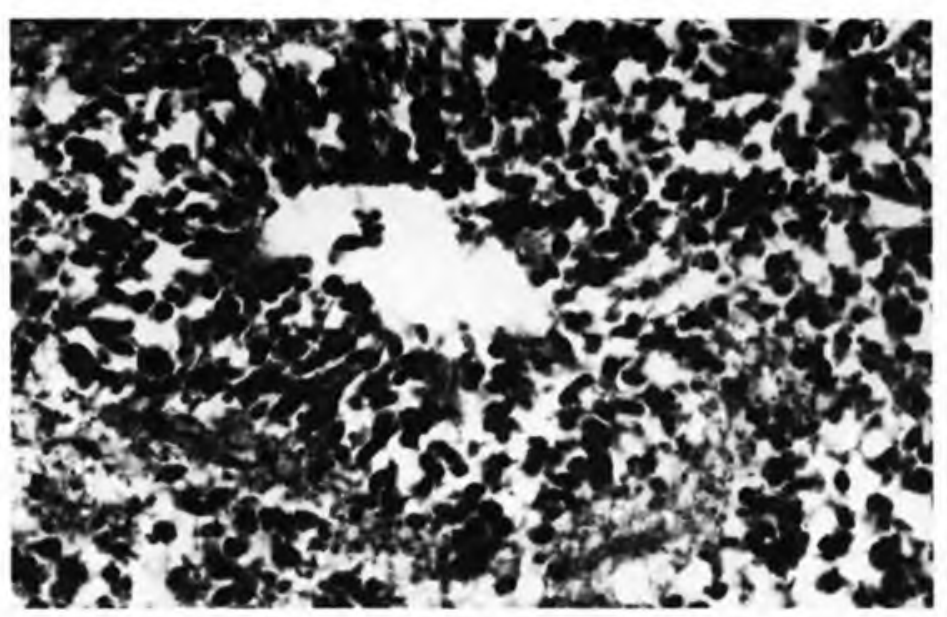

Figura 5

Fotomicrografia de um corte transversal da base da glândula pineal de capivara (Hydrochoerus hydrochoeris) adulta, mostrando a estrutura da base e o comportamento dos cordōes $(C)$ celulares. Coloração H.E. Aumento: $660 x$

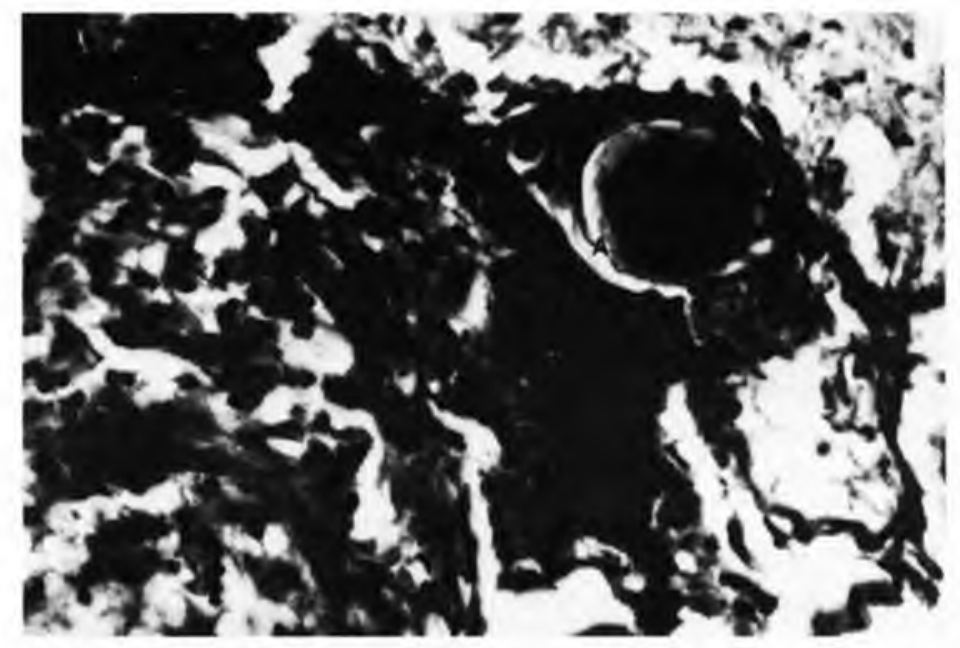

Figura 6

Fołomicrografia do ápice da glândula pineal de capivara (Hydrochoerus hydrochoeris) adulta. O corte mostra em aumento de 165x e 660x uma estrutura arredondada que lembra areia da pineal (A), Coloração H.E.

a uma sćrie de vasos sangüincos, alguns mais perifëricos congestos, delimitados juntamente com a glândula por uma fina capa de kecido conjuntivo. O ápice, por sua ve\%. mostra. cm corte longitudinal, o inicio da formação de uma cavidade.

Os pincalócitos, de um modo geral. arranjam-se em cordōes e concentram-se em deteminadas regiòes do corte. entremeando-se a vasos sangïíneos, kecido conjuntivo e células ncurogliais (Fig. 4). ('om citoplasma abundante e núcleos arredondados os pincalócitos mostram condensaçós de grânulos nucleares (Fig. 4). Nos cortes transversais encontramos ao nivel da base. cordós de pinealócitos, alguns com nucleos mais procminentes e escuros (Fig. 5).

O aipice da glândula mostrou, cm corte transversal, a cavidade da pincal c a cápsula conjuntiva que rodela a glândula, com vários vasos sangüineos dispostos perifericamente.

Encontramos no apice da glandula uma estrutura arredondada, escura, que lembra concreça calcaria (Fig. 6). 


\section{DISCUSSÃO}

De cor acinzentada, tendendo ao castanho escuro na cutia e ao branco perolado, às vezes ligeiramente acastanhado, na capivara, a glândula pincal destaca-se do tecido nervoso diencefálico por ser mais escura na cutia (Silvino ${ }^{19}$, 1992), no homem (Ciross ${ }^{12}$. 1977) c cm outras espécics tais como o eqüino e os ruminantes; porém nos suínos (Simòes ${ }^{20}, 1984$ ) ela se apresenata esbranquiçada, à semelhança do que ocorre na capivara, distinguindo-se, neste grande roedor, pelo seu tamanho $(2 \mathrm{~cm}$ em média) e pelos dois grandes pedúnculos de união da sua base com o III ventriculo encelälico.

A morfologia da glândula pineal é particularmente irregular. Nos roedores, seu formato alongado e as dilatações do seu ápice, sua base ou de ambos, fizeram com que Vollrath ${ }^{21}$ (1979) estabelecesse a classificação da morfologia do órgão classificandoo em diversos tipos. Assim distinguimos a pincal da capivara como do tipo $\alpha B C$, encuanto que a da cutia é do tipo $A B C$ ou $A B C$.

O lipo ( $\alpha \mathrm{BC}$ caracteriza-se por possuir um ápice dilatado e a base do mesmo diâmetro. Já o tipo $A B C$ ou $A \beta C$ caracteriza-se por possuir dilalaçòes no ápice e na base do órgão.

De fato, o ápice da pincal da capivara é tão dilatado que apresenta uma cavidade interna. não observada em outros roedores.

A designação das partes da capivara (ápice, haste e base) proposta por Silvino ${ }^{19}$ (1992) devido ao formato alongado da glândula é também contemplada no homem (Chanton; Paniel ${ }^{3}$, 1962), muito embora a parte que denominamos haste seja por ele chamada de corpo.

Levando-se en conta o comprimento e a largura desses pontos da glândula na cutia (aproximadamente $10 \mathrm{~mm}$ ), e a largura de suas partes ( $1,0 \mathrm{~mm}$ de base, $0,8 \mathrm{~mm}$ de haste e $1,5 \mathrm{~mm}$ de ápice), verificamos que o tamanho da glândula na capivara ć bem superior, guardadas as devidas proporções.

Se por um lado, a largura do ápice da glândula é, em média, $0,5 \mathrm{~mm}$ maior que a da cutia, o comprimento total do órgão chega a ser Irês vezes maior na capivara, guardadas as devidas ressalvas relativas ao tamanho do encéfalo. Entretanto, já foi referendado por Jordan $^{1+}$ (1940) que o tamanho da pincal dos mamíferos não se relaciona com o tamanho do cérebro ou o tamanho do corpo do animal.

O lormato alongado da pineal é bem diferente da estrutura em forma de pinha que the deu o nome (Lesson; Lesson ${ }^{17}, 1971$ : Costa; Chavest, 1949; Simôes ${ }^{20}$, 1984) ou mesmo de um pequeno corpo de formato oval cachatado (Schafferet al. ${ }^{18}$, 1909; Kappers ${ }^{16}$, 1947), pirilorme (Favilli", 1931) ou cônico (Di Fiore? 1953; Chanton; Panicl?, 1962; Bailey ef al.', 1973; Hafez'13, 1982; Junqueira: (arneiro $\left.{ }^{15}, 1985\right)$.

Schafferef al. ${ }^{18}(1909)$, afirmaram que no homem a superficie superior da pineal está unida a pia-máter. sendo sua base conectada às comissuras posterior e habenular, enquanto Di Fiore ${ }^{7}$ (1953) concluiu que, no homem, a pineal apresenta uma haste denominada "haste pincal".

Para Bailey ('t al.' (1973), a base da pineal apresenta uma constrição que forma um pedúnculo, o que denominavam pedúnculo ou haste.

Já loi referendado por Vollrath ${ }^{22}$ ( 1981 ) que uma classificação baseada no formato do órgão não seria de todo satisfatória, visto que em alguns mamíferos a pineal não é uma simples estrutura compacta, mas consiste de grupos de células mais ou menos isoladas que podem diferir em função.

A localização da glândula ć baseada, segundo o autor, na parte posterior do esplênio do corpo caloso, que é usado como ponto de referência segundo Blin; Maurin² ( 1956). Deste modo temos pineais subcalosas (primatas e carnivoros), postcalosas (ruminates e eqüinos) e supracalosas.

Nos roedores a situação aponta uma falha nesta classificação. Ela mostra uma grande variação de forma e de posição, de modo que pode ocupar posição sub ou supracalosa ou ambas.

Quanto à situação da glândula, os autores são unânimes em afirmar que ela repousa entre os corpos quadrigêmeos, e quanto às suas conexões (pedúnculos), estas variam em número e posição nas espécies.

Interessante é a projeção da glândula na capivara entre o cérebroco cerebelo, ultrapassando os limites encefálicos, insinuandose para dentro de uma tenda meníngea como se fosse um terceiro olho encontrado nos peixes. Este é um comportamento raro nos mamiferos, e para responder a esta questão serão necessários novos estudos. inclusive dos ossos da calota craniana, para averiguar a semelhança com que ocorre em répteis, aves e peixes.

Considerando agora a estrutura e a organização da pineal da capivara, verificamos à semelhança do que ocorre na cutia, que as diferentes partes da glândula mostram arranjos próprios relacionados aos pincalócitos. Fstas células poliédricas, face à sua organização cm cordões, conferem à glândula um aspecto homogêneo e uniforme, em cortes transversais e longitudinais. Elas são predominantes no parênquima da glândula e mostram na sua maioria citoplasma abundante e núcleos arredondados, sobressaindo-se entre outras, menos numerosas e mais escuras, de citoplasma menos abundante e mais condensado, com núcleos irregulares. Não podemos afirmar que as condensaçòes granulares presentes no núcleo destas células sejam pigmentos de melanina, porém lais estruturas são lembradas quando analisamos os cortes $\mathrm{cm}$ maior aumento.

A morfologia do citoplasma de alguns pinealócitos da capivara, lembra as descriçoes de Vollrath 22 (1981), pois o citoplasma das células é homogêneo, de formato alongado e os núcleos são arredondados e vesiculares.

A caracteristica volumosa das células pineais, evidencia seu aspecto secretor, e as ramilicaçòes encontradas no seu citoplasma já foram observadas por outros autores. De fato, os cortes transversais do ápice da glândula nos mostram a evidente cavidade da pincal c o produto de sua secreção. Esta parece ser mais evidente no ápice da glândula (porçào aparente entre o cérebro e o cerebelo).

A quantidade de vasos sangüineos no tecido conjuntivo que reveste a glândula é muito grande na capivara. Este aspecto é evidente não somente nos cortes histológicos como também na propria anatomia macroscópica da epilise.

Lima cápsula conjuntiva envolve a pineal, a qual de acordo com Bailey et al. (1973) forma trabéculas que penetram no órgão dividindo-o em lobos maldefinidos. Para Dellman; Brown", ( 1975 ) c George et al. ${ }^{11}$ (1985), esta cápsula é oriunda da pia-máter. Os lobos pineais realmente são evidentes nos cortes transversais e longitudinais, porém, para delimitá-los, teriamos que usar coloração 
especifica para tecido conjuntivo. l:meretanto pelo fillo de o lecido conjuntivo constituir o Irajeto de vasose (Junculeiral: (arneirol". 1985: (ieorge al al." 1985), a division acaba sendo evidente nas nosisals preparacioss.

(oncluindo, cabe constatar a presença de estruturas que lembram a arcial cerchral ou concreçós calcáreass na pincal dat capicara. Lssas estruturas são descrilas na literatura por Schatfler et al. ${ }^{12}$. 1909: Favilli". 1931: Jordan'4. 1940) Di Fiore?. 1953: Kalppers 16. 1963: (ianneng"', 1968; Dellman; Brown", 1975: Wheater

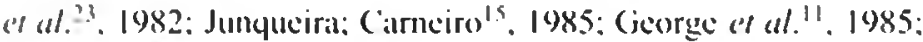
Dice el al. ${ }^{5} .1990$.

\section{CONCLUSÕES}

1. A glandula pincal da capivara (Mydrochooms hedrecherers) e umo órgào alongado. Identificamos na glândula pincal três porçòes. ou seja. unna basc, que se conectal com o kecido nervoso attraves de dois pendinculos, um ajpice, que se insinua entre os hemisferrios cerchrais e ecrebelo e uma haste. que une as duas primeira porçès. 2. () comprimento total da glandula. incluindo a basc, a haste en o apice é dal ordem de 0.5 a $3.0 \mathrm{~cm}$. cm média $2.2 \mathrm{~cm}$ nos animats adultos e $1,0 \mathrm{~cm}$ nos jovens.

A largura media da basce, hasse c ápice foi igual a $1.3 \mathrm{~mm}: 1.2 \mathrm{~mm}$; 2.0 $\mathrm{mm}$ para os adultos c $0.8 \mathrm{~mm}$; $0.6 \mathrm{~mm} ; 1.3 \mathrm{~mm}$ para os josens. 3. Istruluralmente, a glândula pineal da capis aral estit constituida principalmente por células poliédricals (pincalocitos), als quatis possuem citoplasma abundante e nicleos arredondados, com condensalçoes granulares.

Arranjam-se em tileiras formando cordoess e no seu conjunto conferem à glândula um aspecto homogêneo e uniforme.

4. Nos cortes transversais do ajpice da glandula pincal da calpicara. encontramos formaçós arredondadas entremeadas ans pincalocilos. que lembram as conereçoes calcarias do pincal dos outros mamiferos.

\section{SUMMARY}

The pineal gland was studied macro-and microscopically in 19 adult and young capybaras (Hydrochoerus hydrochoeris) 13 females and 6 males. Pineal gland was present in all specimens between the cerebrum and the cerebellum and was formed by a base with two peduncles, a stem and an apex. The gland was in the roof of the III ventricle, next to the rostral coliculi, either whish or brownish. The apex contained a cavity. Pineal gland was $2.2 \mathrm{~cm}$ long, and dimensions of the base. stem and apex were $1.3 \mathrm{~mm} .1 .2 \mathrm{~mm}$ and $2.0 \mathrm{~mm}$ respectivelly. The connective tissue capsule at least in part. contained blood vessels. Pineal parenchyma exhibited pinealocytes, with nuclear and interstitial cells.

\section{UNITTRMS: Pineal body: Capybaras; Hidrochaerus.}

\section{REFERENCIAS BIBLIOGRÁFICAS}

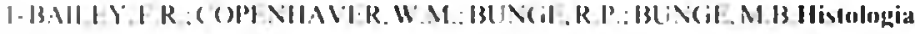

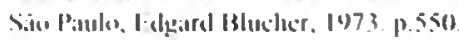

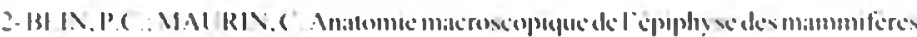

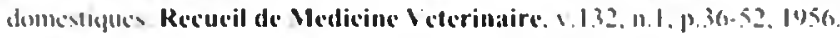

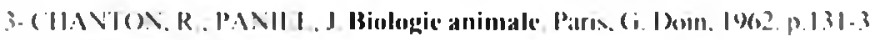

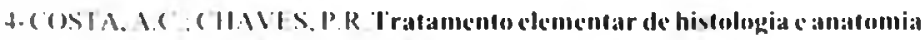

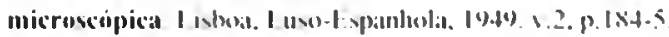

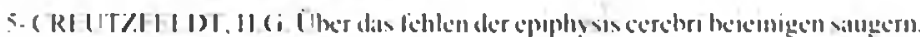
Analomischer Ineciger, 1.42, n.20:21, p.517-21, 1013.

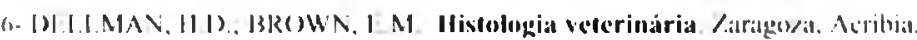

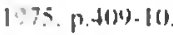

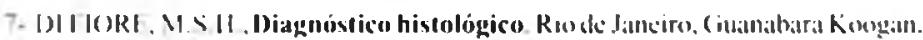
105.?. 1.2. p. 721

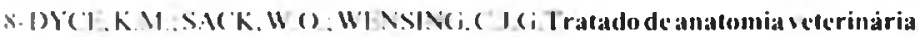

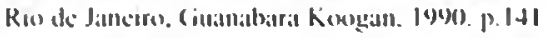

9. I AVIL I.I. N Vorioni comparate di anatomia e fisiologia deqli animali rurali

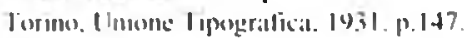

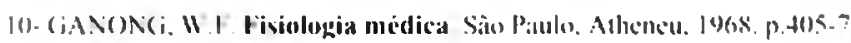

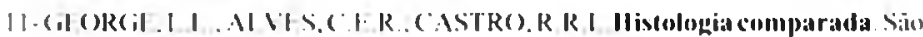

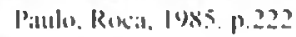

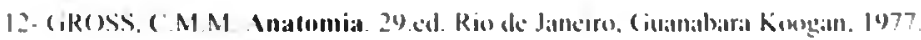
1.2. p.129)3..4

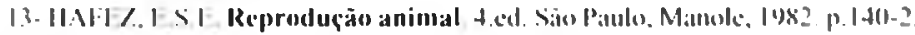

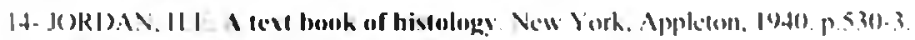

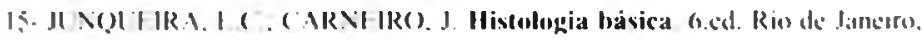

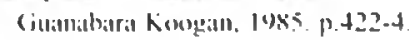

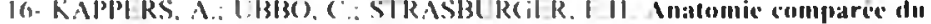

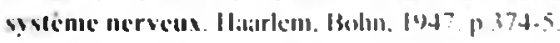

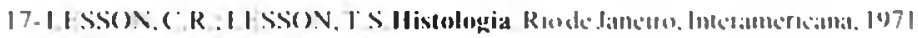
p.t13.4.

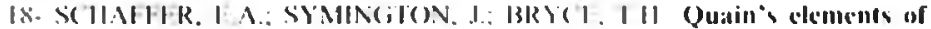

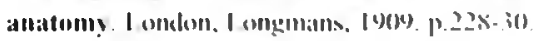

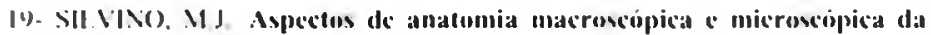

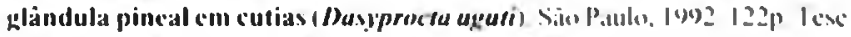

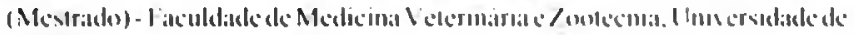
Simo l'anlo.

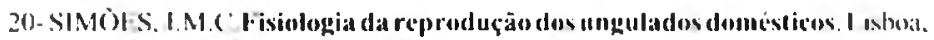

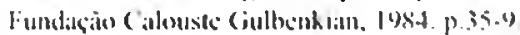

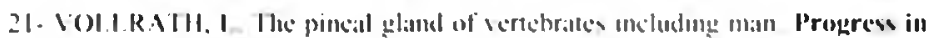
Brain Rescarch. 1.52, n. 1, p..25-3.3. 1974).

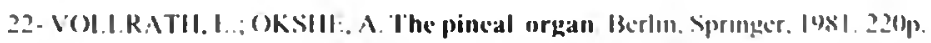

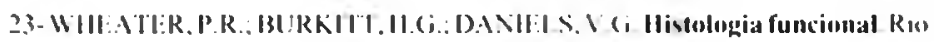

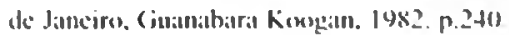

Kecebido para publicação: 26/01/95 Aprovado para publicação: (14/107/97 